\title{
Comparing centralized vs. decentralized nursing unit design as a determinant of stress and job satisfaction
}

\author{
Francine M. Parker ${ }^{1}$, Sarajane Eisen ${ }^{2}$, Jennifer Bell ${ }^{3}$ \\ 1. School of Nursing, Auburn University, USA. 2. Skylight Art Services, Fort Worth, TX, USA. 3. Department of Teacher \\ Education, Columbus State University, Columbus, Georgia, USA
}

Correspondence: Francine M. Parker. Address: 222 Miller Hall, Auburn University 36849. Telephone: 334-844-6759. Fax: 334-844-5654. Email: parkefm@auburn.edu

Received: December 4, 2011

Accepted: April 20, 2012

Published: November 1, 2012

DOI : $10.5430 /$ jnep.v2n4p66

URL: http://dx.doi.org/10.5430/jnep.v2n4p66

\begin{abstract}
The purpose of the study was to determine the effect of the nursing unit design on stress and job satisfaction. The Perceived Stress Scale (PSS) and Demand-Control-Support Questionnaire (DCSQ) were administered to 40 nurse participants to evaluate staff stress, job satisfaction, and perceptions of work environment. In addition, two follow-up focus groups were conducted to expand upon the collected survey data. Results suggest that the centralized floor lends itself to better patient access and professional communication. Further research is needed regarding nurse burn-out and turn-over as it relates to the designed work environment.
\end{abstract}

\section{Key words}

Nursing unit design, Stress, Job satisfaction

\section{I ntroduction}

Historically, the nursing workforce has managed high turnover rates, increased acuity levels, and evolving staffing patterns reflective of managed care initiatives. However, the current shortage of qualified nurses is a critical concern to health care administrators within the United States and beyond. An aging nursing workforce is estimated to bring turnover rates to approximately $20 \%$ yearly ${ }^{[1]}$. The nurse population is expected to grow six percent between the years 2000-2020, while the demand for nurses in the US is expected to grow by $40 \%$ during the same time period ${ }^{[2]}$. This unrelenting nursing shortage combined with the aging nurse population creates a challenging situation to be addressed by nurse leaders and health care administrators within the next ten years ${ }^{[3]}$. A creative approach that is reflective of technological advancements in point of care and responsive to the generational makeup of the nursing workforce is fundamental to a unit design that is both functional and efficient, yet promotes a positive environment and cohesion among staff ${ }^{[4]}$. One such approach involves assessing the designed layout of nurse units as supportive of technological advancement and stress mitigation. Various nurse unit designs can affect the efficiency of patient care through ready accessibility to patient rooms, information from other staff and medical information. Unit design can also contribute to noise levels with centralized nurse units typically having the higher level of noise since they are a central gathering area for all nurse staff ${ }^{[5]}$. Common environmental stressors in the work environment can be stressful to staff and influence job satisfaction and, ultimately, intention to change jobs. Mitigating or eliminating these environmental factors has the potential to improve staff satisfaction and retention. Stress influences nursing job satisfaction and, ultimately, intention to change jobs ${ }^{[5]}$. While a 
large amount of data has been generated regarding stress as it relates to workload, psychosocial factors and environmental stressors, there is little research assessing the physical environment of nursing unit design as it relates to nurses stress and job satisfaction.

With health care facilities in the United States undergoing the largest building transformation in the country's history, it is imperative that data be generated to define a supportive nursing work unit ${ }^{[6]}$. With nurses comprising the largest entity of health care workers in acute care settings, there is considerable need for evidence-based research to determine the type of work unit design that is most psychologically and physically supportive. A key responsibility of administrators working in collaboration with academic researchers is to challenge and investigate such emerging design trends as that of nurse unit design. According to study ${ }^{[7]}$ in acute care settings, it was revealed that any inadequacy in the physical environment would contribute to staff fatigue, stress, and burnout. According to the study ${ }^{[8]}$, previous research has clearly demonstrated the importance of communication for improving care quality and staff satisfaction, but less attention focused on the physical environment of the nursing unit to influence communication patterns .... and as part of a the larger scope of environmental elements, the contribution of the physical environment can be significant.

\subsection{Background}

The physical design features and social climate of nurse work environments are thought to influence staff turnover ${ }^{[9,10]}$. A key element affecting quality patient care delivery is stress, as it relates to the work environment. The presence of stress among the nursing workforce has long been of interest to health care administrators, nurse leaders and researchers. Stress affects job satisfaction with subsequent adverse retention, attrition, absenteeism and burnout consequences ${ }^{[11-13]}$ found job stress to be negatively related to job satisfaction among a sample of 241 hospital nurses in a university medical center setting. Heavy patient workloads and stress have been reported to have a negative impact on job satisfaction ${ }^{[14]}$. Work environment variables, such as job satisfaction, were linked to the perception of quality care provided as revealed in research that examined work environment and nurse outcomes. Job satisfaction was reported as highest when the nurses perceived that quality care was delivered. Nurses who did not perceive quality care was being delivered reported high levels of job pressure and role tension ${ }^{[15]}$.

Researchers contend that aversive physical characteristics can generate negative reactivity affecting stress, sense of personal control and well-being ${ }^{[16]}$. Stress, according to Zimring, $\mathrm{C}^{[17]}$, can result from the dynamic interactions of person and environment if there is a misfit between individuals' attributes and environmental attributes. The design of the environment affects the coping processes used to resolve person-environment misfits, which can induce or assist in stress mitigation. Stress occurs in individuals when their situation is overly complex, ambiguous, and unclear, as well as highly demanding ${ }^{[18]}$. According to Cunningham, W. J. ${ }^{[19]}$ when the individual becomes unable to cope with an enduring source of stress, a behavioral manifestation, commonly labeled burnout, may occur. Burnout is used to describe the cumulative effects of stress experienced by those who work in occupations subject to constant tension, such as nursing with inherent high performance expectations. Manifestations of burnout syndrome can range from fatigue and irritability to exhaustion and depression ${ }^{[20]}$. Incumbent upon health care administration is to create an environment where stress is mitigated to the extent possible, where the nurse staff environment is psychologically supportive.

Nursing staff needs to be supported through the affordance of a physical work environment conducive to their functional, behavioral and psychosocial needs ${ }^{[21]}$. However, it appears that nursing unit design generally has had little attention in hospital planning during past decades ${ }^{[6,22]}$. With healthcare focused on patient-centered care delivery, the design of nursing units has revolved around the patient room and the immediate area surrounding the patient ${ }^{[22]}$. In the last twenty years, health care providers began to realize that attention and resources were well invested in redesigning nursing unit environments. Research on the physical environment of healthcare facilities related to patient outcomes is available, yet there appears to be insufficient focus towards nurse staff well-being in the healthcare setting and that not enough attention has been directed towards the relationship between the physical design for nurse units, their health, performance and job satisfaction ${ }^{[6]}$. Environmental studies, such as the current, to investigate work unit design as a factor in nurse stress and job 
satisfaction are important to build a knowledge base for further exploration and research. By definition, the centralized nurse station serves as the information hub of the unit, with all patient information disseminated from a central location. Nurses, physicians and other members of the health care team access and process patient related information at this central station. Inherently, a centralized unit is a noisy environment because of the occurrence of these ongoing interchanges.

Decentralized unit design has revealed considerable improvement to the inherent problems of the central station ${ }^{[23]}$. In a decentralized nurse unit design, often referred to as a series of 'pods', nurse staff workspaces are placed throughout the unit. These pods can be located at the center of a small set of patient rooms (ex. 4-6 rooms) or directly outside patient rooms. The workspace usually contains a window that allows the nurse to observe the patient.

The researchers' interest in the effect of nursing unit design on stress and job satisfaction stems from the fact that decentralized pods are emerging as "best practice" in current nursing unit design, although there is little methodological research confirming that pods are used by nurses as intended, which might affect the staff experience within these environments. Nor has their influence on communication and interaction patterns (as opposed to improving patient observability or reduced nurse walking time and fatigue) been considered ${ }^{[24]}$. According to study ${ }^{[25]}$ when the environment is perceived to be uncertain, it is important to have social support systems, particularly a supervisor who is perceived as supportive, to help nurses cope with the emotional exhaustion. By the inherent design of a decentralized nurse unit design, supervisors are not readily available for such support. In the case of whether nursing unit design influences interaction patterns, our preliminary data from Becker's study ${ }^{[24]}$ suggest that the new, more decentralized unit has significantly decreased the frequency of interaction among nurses, and between nurses and doctors. In addition, according

to ${ }^{[26]}$ study, on the decentralized units significantly less time was spent consulting with other medical staff when compared with the centralized units (within hospitals and across hospitals). In addition, observed social interactions were significantly higher in the centralized units (across hospitals) than in decentralized units providing additional evidence of the importance of social behavior in nursing station design. Discussions ensue regarding the advantages of a centralized nurse unit versus a decentralized unit.

\subsection{Objectives}

In this study, the research team assumed there was a significant correlation between the designed environment of nursing units and nursing staff stress and job satisfaction levels. The design of a centralized and decentralized nursing unit was explored and compared to determine the impact on nurses' psychological well-being, as determined by stress level and job satisfaction.

The following hypotheses were investigated:

1) Nurse perception of the supportive quality of the physical work environment is rated higher on centralized than decentralized units.

2) Nurse job satisfaction is rated higher on centralized than decentralized units.

3) Nurse stress levels are rated lower on centralized than decentralized units.

4) Nurse perceptions of the psychological impact of the work environment on their overall well-being are rated higher on centralized than decentralized units.

\section{Methods}

The protection of human subjects was ensured through approval from the University's Institutional Review Board (IRB) as well as the Hospital Research Board (HRB). Two research instruments were used to compare centralized and decentralized nursing unit design for the impact on nurses' stress and job satisfaction. Once participant surveys were completed, two focus group interviews were scheduled within 3 weeks and the nurses who completed the surveys were 
invited to attend. The focus group interviews served as follow up to secure additional information on staff reactions, perceptions and experiences within the two different unit designs.

It is important to note that researchers often use the multi-method approach to enhance validity. Multi-methodology research design encourages the researcher to approach their research questions from different angles. This multi-method approach, often referred to as triangulation, refers to different investigative methods applied to one research entity ${ }^{[27]}$. Using a variety of methods reduces the possibility of bias due to a particular methodology or the omission of significant issues, and it also increases validity. Fitzpatrick, R., \& Boulton, M. ${ }^{[28]}$ provide a constructive definition describing multi-methodology as the use of as wide a range of sources as possible in order to support certain hypotheses. Zeisel, J. ${ }^{[29]}$ advocated the use of triangulation because different traits of a complex phenomenon can be observed by using multiple tools to reduce possible errors. Qualitative and quantitative data can cross-validate each other for a common reference point, generating more unbiased research results.

\subsection{Setting}

A 340-bed regional hospital in southeastern United States that houses a referral center with an active medical staff of more than 145 physicians and 450 full time registered nurses was the site of the study. The medical center serves a five county area and offers programs and services in nearly every medical specialty including a full range of inpatient and outpatient procedures.

Two nursing units within the hospital were selected with guidance from the Chief Nursing Officer: one with decentralized and one with a centralized nursing unit design. Each floor was comprised of 36 total patient beds. The eighth floor was comprised of the Progressive Care Unit (PCU) and Cardiac Special Unit (CSU) with decentralized unit designs (pod units), each with 18 beds. The pod units are supported by a centralized information center, staffed as an information resource hub for a patient's family and/or visitors. The nurse to patient ratio at the time of the study was 3:1. The second unit selected was a 36-bed medical-surgical unit on the seventh floor classified as centralized unit design. The nurse to patient ratio on this floor was 6:1. The variance of the nurse to patient ratio is an inherent design factor of the decentralized versus centralized unit design. Where the decentralized pod design has a single specified nurse for a specific number of patients, within a centralized nurse unit, nurse staff are based out of a single unit location and provide inter- patient-support for the other nurse staff.

\subsection{Study population}

The sample for this study comprised forty registered nurses, currently employed full time at the hospital and working on one of the 2 nursing units selected for the research. The median age of the nurses was thirty seven. Thirty eight of the participants were female and 2 were male. Years of nursing experience ranged from 1 to 5 years.

\subsection{I nstrument}

Informative flyers describing the research were posted in visible locations on each of the two select floors two weeks prior to Invitation to Participate and Informed Consent letters distributed to the nursing units by hard copy as well as through the hospital secure email system. A nurse desiring to participate was directed to complete the Informed Consent and return by email attachment after which time a link to access the two survey instruments was provided. The surveys were available via the secure online survey and research site Survey Monkey.

The Perceived Stress Scale (PSS) survey measures the nurse's perception of degree to which situations in one's life are appraised as stressful. The Perceived Stress Scale is considered a widely accepted measurement of stress ${ }^{\text {[30] }}$. This 14 -item questionnaire, based on a 5-point scale asks the respondent how often certain experiences of stress occurred in the last month. The content of the questionnaire items are nonspecific. Survey questions included: 1) In the last month, how often have you been upset because of something that happened unexpectedly? 2) In the last month, how often have you felt nervous and "stressed"? 3) In the last month, how often have you found that you could not cope with all the things you had 
to do? Stress, as opposed to challenge, is believed to result from experienced overload with further emphasis on experienced unpredictability and uncontrollability of events. This implies that the existence of stress in a person is partly inferred from information on the person's experience of lack of control. Two survey items directly address "stress" or "hassles", three refer to situations of overload, whereas nine items refer to uncontrollable, unmanageable, or unpredictable situations ${ }^{[30]}$. Thus, the PSS focuses on a more cognitive appraisal of stress and the respondent's perceived control and coping capability.

The Perceived Stress Scale evaluated Hypotheses 2: Nurse Staff job satisfaction is rated higher on centralized than decentralized units, and Hypotheses 3: Nurse Staff stress levels is rated lower on centralized than decentralized units. You can report the reliabilities and validity of the instruments found in your current study.

The Demand-Control-Support Questionnaire (DCSQ), a previously modified version of Karasek, et al. Job Content Questionnaire (JCQ) (1998). The Demand-Control-Support-Questionnaire (DCSQ) ${ }^{[31]}$ survey contains 14 questions on a five-increment rating scale regarding nursing unit design and the implications on nurses' well-being and job satisfaction. Survey questions included: 1) How would you rate the social support on your nursing unit? 2) Are supply rooms located conveniently for patient care needs on your nursing unit? 3) How easy is it to manage charting, phone calls, doctor visits, and computer work in this area? Karasek and Theorell recognized that occupational stress and illness, or work satisfaction and effectiveness, arise from an interactive dynamic between the challenges (demands) presented by work tasks in relation to the resources (controls or decision latitude) that workers bring to bear in response to job demands. Central to this model is the interaction between job demands and job control. It assumes two main hypotheses: (1) the combination of high job demands along with low job control precipitates psychological and physical strain (high strain jobs); (2) jobs in which both demands and control are high lead to well-being, learning and personal growth (active jobs) ${ }^{\text {[31] }}$. Based upon the stated hypotheses, the DCSQ instrument was employed for this research study. The article ${ }^{[32]}$ used Karasek’s Demand-Control Support- Questionnaire instrument to examine the degree to which job strain in nursing work environments affected staff nurses' perceptions of empowerment, work satisfaction, and organizational commitment. Nurses who experienced high job strain were significantly less empowered, less committed, and less satisfied with their jobs than those who reported lower levels of job strain. Another study using the Karasek model looked at occupational stress of district nurses in Stockholm to compare sources of stress and to analyze psychological working conditions, such as job demands, control, and social support. The researchers also evaluated the effects of occupational stress on job satisfaction, commitment, health and psychological well-being. Findings indicated that satisfaction was negatively correlated with job demands, perceived control, level of influence, and resources in both countries ${ }^{[33]}$. Further support for Karasek's model was shown in a study comparing nurse aides and registered nurses ${ }^{[34]}$. Nurse aides showed significantly higher psychological job demands and strain than registered nurses. Limited social support and restricted control or decision latitude has also been associated with distress in student nurses ${ }^{[35,36]}$.

In the current study, the DCSQ survey evaluated Hypotheses 3: Nurse staff stress levels are rated lower on centralized than decentralized units, and Hypotheses 4: Nurse staff perceptions of the psychological impact of the work environment on their overall well-being is rated higher on centralized than decentralized units.

In order to be confident that these scales provide accurate measurements, reliability analyses were conducted. Results for the reliability analyses are presented in Table 2. With Cronbach's alpha of .50 or greater as a criterion, these results suggest that the scales within the survey are internally consistent measures, except for the Perceived Stress Level for the decentralized group. The alpha coefficients ranged from .34 to .68. With the Perceived Stress Level scale, two questions had a negative effect on the alpha coefficient; however, these questions differed for each group so they were left in the analyses. Given these analyses indicating that the measures are reliable, meaningful subsequent analyses were justified. 


\subsection{Focus groups}

The opportunity to participate in the study spanned 3 weeks after which time the survey site was no longer available to the nursing staff. Within 2 weeks of the conclusion of survey data collection, two focus group sessions were scheduled. A flyer with information regarding date, time, and location within each participating hospital floor was posted. Additionally, the nurse manager from each unit verbalized an invitation to participate to the nursing staff. All nurses who completed the surveys were invited to attend. One separate focus group interview was conducted with nurse staff from the two participating nursing units. A total of 14 nurses participated with nine nurses from the centralized group and five nurses from the decentralized group. Nurse participants representing centralized and decentralized units volunteered to attend one of two scheduled focus group interviews. Focus groups interviews were held with each group on the hospital premises in a closed meeting room. Five semi-structured interview questions, developed by the research team, guided discussion during the focus group sessions.

Interview questions included: 1) How do you feel the design of your nursing unit affects your overall health (ex. walk distances, stress experienced)? 2) How do you feel the design of your nursing unit design facilitates professional and social communication? 3) What are your experiences of workflow and efficiency related to the design of your nursing unit? 4) How do you feel the design of your nursing unit supports nurses' multitasking and chart documentation? and 5) How do you feel the design of your nursing unit supports patient delivery care?

Follow-up questions were then posed to further expand data obtained from the surveys on nurses' psycho-physiological well-being and job satisfaction. Focus group interviews were tape recorded with participants' permission. Following the session, the responses were transcribed by the Primary Investigator after which the recordings were destroyed. The two dual moderators, which were the two primary researchers, conducted the focus groups with the duration of each meeting approximately one hour.

\section{Results}

\subsection{Participant demographics}

The Perceived Stress Scale and the Demand-Control-Support Questionnaire instruments were administered to 40 nurse participants who worked at a southeastern hospital. The participants included 6 (15\%) males and 34 (85\%) females. Of these participants, 39 (97.5\%) were RNs and 1 (2.5\%) was a multi-care technician. The participants ranged in age from 20 to over 60; 42.5\% ( $n=17)$ of the participants reported their age between 20 and 30, 20\% $(n=8)$ reported their age between 31 and 40, 35\% (n=14) reported their age range to be between 41 and 60, and 2.5\% (n=1) reported an age of over 60 .

The years of experience ranged from less than 1 year to over 10 years. When specifically asked about the total years of experience within the nursing unit, $15 \%(\mathrm{n}=6)$ of the participants reported less than 1 year, $50 \%(\mathrm{n}=20)$ reported between 1 and 5 years, $10 \%(n=4)$ reported 6 to 10 years, and 25\% (n=10) reported over 10 years. The total years of nursing experience $(r=.80 ; p<.001)$ and the total years of experience at the hospital $(r=.89 ; p<.001)$ had similar proportions. Based on the floor plan of the nursing unit, the participants were grouped as decentralized $(n=29)$ or centralized $(n=11)$ for the purpose of this study. Table 1 reports gender, age, and years of experience by each nursing unit.

In order to be confident that these scales provide accurate measurements, reliability analyses were conducted. Results for the reliability analyses are presented in Table 2. With Cronbach's alpha of .50 or greater as a criterion, these results suggest that the scales within the survey are internally consistent measures, except for the Perceived Stress Level for the decentralized group. The alpha coefficients ranged from .34 to .68. With the Perceived Stress Level scale, two questions had a negative effect on the alpha coefficient; however, these questions differed for each group so they were left in the analyses. Given these analyses indicating that the measures are reliable, meaningful subsequent analyses were justified. 
Table 1. Gender, Age, and Years of Experience by Floor Plan

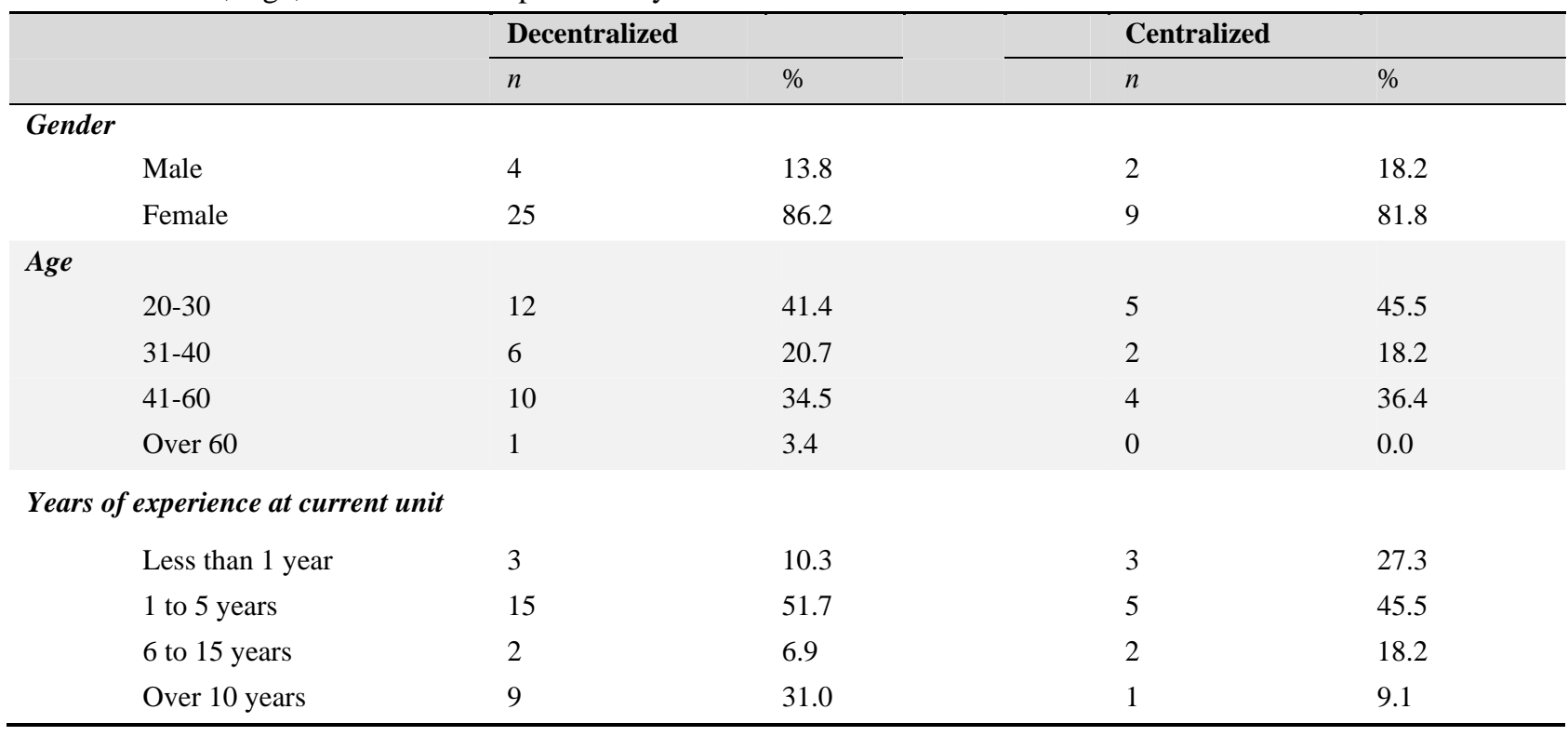

Table 2. Survey Scales: Analysis of Reliability

\begin{tabular}{lll}
\hline \multirow{2}{*}{ Scale } & \multicolumn{2}{c}{ Alpha Coefficient } \\
\cline { 2 - 3 } & Decentralized & Centralized \\
\hline Work Environment & .54 & .68 \\
Perceived Stress Level & .34 & .58 \\
\hline
\end{tabular}

\subsection{Work environment}

An analysis of variance was conducted with the survey data to determine if the work environment means differed significantly by group. The mean difference was not statistically significant $\left(F(1)=1.31 ; p=.26 ; \eta^{2}=.03\right)$. The mean score for the decentralized group was 4.26 with a standard deviation of 0.35 . The mean score for the centralized group was 4.40 with a standard deviation of 0.34 . The centralized group tended to be slightly more satisfied with their work environment than the decentralized group, which indicated a higher satisfaction with the work environment for the centralized group.

Despite the survey results which lacked statistical significance, the data collected during the focus group depicted differences between the nursing units. Nurses, who participated in the focus group from the centralized floor, commented that the floor plan enabled the nurses to have more access to the patients, records, and medications. This increased access allowed them to provide better patient care delivery. "Most of the time, someone [is] available at nurses' station," remarked a nurse. With regard to the physical design, another nurse stated that the U-shape design allowed for more visibility, but could be "difficult if you had patient on both ends." If the nurses were in a facility with higher patient capacity, the layout of the rooms may affect the overall efficiency.

On the decentralized floor, one nurse stated that it was "easier to find us if [a] patient needs us." But, another nurse commented, if a nurse is needed, "families sometimes have to search all pod areas." A nurse from the centralized floor commented that someone might call the decentralized floor information desk and "not find a nurse to pick up phone." On the other hand, a nurse from the decentralized floor stated that a patient called for a nurse on the centralized floor four times, but a nurse did not come to assist them. This disagreement concerning the decentralized floor was biased based on the data collected. The inconsistent responses could be contributed to factors other than the work environment. Other nurse observations from the decentralized floor included "we try to be efficient," "we like patients together," and "everything is close except charts". 
The comments from both groups support the idea that a centralized floor plan allows for greater access to the patients, higher levels of efficiency, and more efficient patient care delivery. The decentralized floor plan may inhibit patient access and efficiency, but the nurses in that nursing unit work to overcome any obstacles that may affect efficient patient care.

\subsection{Perceived stress level}

An analysis of variance was conducted with the survey data to determine if the means differed significantly by group. The mean difference was not statistically significant $\left(F(1)=0.86 ; p=.36 ; \eta^{2}=.02\right)$. The mean score for the decentralized group was 3.31 with a standard deviation of 0.27 . The mean score for the centralized group was 3.39 with a standard deviation of 0.26 . The means for both groups were virtually equal for the perception of stress.

The nurses, who participated in the focus group, provided various comments regarding the positive effects of the nursing unit on professional communication and social communication. Nurses on the centralized floor commented that the nursing unit allowed them to connect and communicate with other people. This communication contributed to the "continuity for patients." According to a nurse on the centralized floor, there was one medication error during a 6-month period. One nurse stated that the layout was a "negative" because "nurses chat". A nurse from the decentralized floor commented that the centralized nursing unit "looks like too much space for socialization". The following statement, from a nurse on the centralized floor, summed up the nurses' feelings about the nursing unit, "you are never by yourself always have someone to ask". Several nurses on the centralized floor noted that there were no current staff vacancies on the floor, that the floor had high retention rates, and that "nurses want to come to work on centralized unit".

Conversely, the nurses on the decentralized floor painted a different picture of the professional and social communication in their nursing unit. One nurse stated that the "primary nurse knows what's going on", but other nurses do not "know what's going on with other patients". Another nurse supported the previous professional communication illustration by stating that one "can go all day without seeing anyone". Other nurses commented that the floor lacked a team atmosphere, had "stressed nurses," and required one to "find working relationships".

Personnel from both nursing units had a consensus about the use of technology that required the nurses to multitask and its effect on the perceived stress level. A nurse from the centralized floor commented that the "focus toward everything going electronically does not take place of face to face" and a nurse from the decentralized floor stated that nurses need more training to use the technology. These statements attest to how the use of technology affected the perceived stress level in both nursing units.

The focus group data from both nursing units portrayed potential differences in perceived stress levels among the nursing units. The nurses on the centralized floor had a greater sense of teamwork and camaraderie compared to the decentralized floor who felt more isolated. While a few nurses thought the increased communication was a negative, the majority felt the centralized floor plan was more beneficial for professional and social communication.

\section{Limitations}

The first limitation of this study was the small sample size which limits generalization of the findings to all nursing unit designs. Secondly, data was collected in one region only, thus the generalizability of the findings to other health care institutions or regions may be limited. Thirdly, the study was conducted in a single hospital, rather than multiple hospital sites, where staff may have had limited exposure to different types of nursing unit designs. A fourth limitation was that every nurse participant had not worked in both a centralized and decentralized work unit and thus had little frame of reference to compare one unit to the other.

In view of the these preliminary findings, with the lack of statistical significance generated from the two surveys, the focus group interviews provided valuable insight beyond the survey responses into how the nurse staff experience their respective units. There was much greater job satisfaction and camaraderie among the nurse staff of the centralized unit, which suggests that this unit provides an environmental element of support of not only the facilitation of work and social 
support, but also stress reduction. The differences in the nurse to patient ratio between the two nurse units (double that on the centralized units) without any statistical differences in stress levels indicates that the lower ratio on decentralized unit does not appear to affect the stress levels. Until there is further data generated, results from this study indicate that a potential solution to nurse unit design would be a hybrid of both centralized and decentralized units that could meet the need for patient-centered delivery and the social/communication support necessary for nurse job satisfaction. Chart access \& rendering \& processing of orders is becoming more decentralized - which would be an advantage of a centralized nursing unit design. On the basis of these findings, additional research is suggested concerning nurse burn-out and turn-over as it relates to the designed work environment. While perceptions of nurses may differ from various nurse work units research efforts to explore and explain these differences have not been widely undertaken. There is need for further research to provide insights as to how the environment can best support nurse staff in delivering quality, safe patient care and concurrently mitigate unnecessary stress and increase job satisfaction.

\section{Conclusion}

The definitive design for nurse units is not specifically a centralized versus a decentralized model, but a balanced blend of both. The importance of nurse units that support efficient patient care delivery, stress mitigation, and job satisfaction are ones which support characteristics of centralized (effective communication, consultation, and social support), coupled with decentralized (direct patient care and increased demands of technology).

\section{Presentation at a meeting}

Organisation: Health Care Design Conference 2010

Place: Las Vegas, Nevada

Date: November 2010

\section{References}

[1] JCAHO. 2002. Joint Commission on Accreditation of Healthcare Organizations: Healthcare at the crossroads, strategies for addressing the evolving nursing crisis, retrieved, 06/11/2006. Available from: www.jointcommission.org/NR/rdonlyres/5C138711-ED76-4D6F-909FB06E0309F36D/0/health_care_at_the_crossroads.pdf

[2] HRSA. 2006. Health Resources and Services Administration, Bureau of Health Professions, National Center for Health Workforce Analysis: Projected supply and shortages of registered nurses: 2000-2020, retrieved 06/11/2006. Available from: www.bhpr.hrsa.gov/healthworkforce/reports/mproject/default.htm

[3] Hendrich, A. L., Fay, J., Sorrells, A., K. Effects of acuity-adaptable rooms on flow of patients and delivery of care. American Journal of Critical Care. 2004; 13 (1): 35-45. PMid:14735646

[4] Shader, K., Broome, M. E., Broome, C.D., West, M. E., Nash, M. Factors influencing satisfaction and anticipated turnover for nurses in an academic medical center. JONA. 2001; 31(4): 210-216. http://dx.doi.org/10.1097/00005110-200104000-00010

[5] Applebaum, D., Fowler, S., Fiedler, N., Osinubi, O., Robson, M. The Impact of Environmental Factors on Nursing Stress, Job Satisfaction, and Turnover Intention, Journal of Nursing Administration. 2010; 40(7/8): 323-328. PMid:20661062 http://dx.doi.org/10.1097/NNA.0b013e3181e9393b

[6] Ulrich R, Zimring C. The Role of the Physical Environment in the Hospital of the 21st Century: A Once-in-a-Lifetime Opportunity. Concord, CA: The Center for Health Design. 2004.

[7] Chaudbury, H., Mahmood, A., Valente, A. The Effect of environmental design on reducing nursing errors and increasing efficiency in acute care settings. Environment \& Behavior. 2009; 41(6): 755-786. http://dx.doi.org/10.1177/0013916508330392

[8] Becker, F. At one with your surroundings? Nursing Management. 2009; 40(8): 24-27. PMid:19667916 http://dx.doi.org/10.1097/01.NUMA.0000359205.44705.6d

[9] George, L. K. Quality of care in nursing homes: Attitudinal and environmental factors. Durham, North Carolina: Center for the Study of Aging and Human Development, Duke University Medical Center. 1979. 
[10] Bergman, R., Eckerling, S., Golander, H., Sharon, R., Tomer, A. Staff composition, job perceptions, \& work retention of nursing personnel in geriatric institutions. International Journal of Nursing Studies. 1984; 21: 279-93.

http://dx.doi.org/10.1016/0020-7489(84)90020-8

[11] Khowaja, K., Merchant, R., Hirani, D. Registered nurses perception of work satisfaction at a Tertiary Care University Hospital. Journal of Nursing Management. 2005; 13: 32-39. PMid:15613092 http://dx.doi.org/10.1111/j.1365-2834.2004.00507.x

[12] Ruggiero, J. S. Health, work variables and job satisfaction among nurses. Journal of Nursing Administration. 2005; 35 (5): $254-263$. http://dx.doi.org/10.1097/00005110-200505000-00009

[13] Shader, K., Broome, M., Broome, C., West, M.E., Nash, M. Journal of Nursing Administration. 2001; 31(4): $210-216$. http://dx.doi.org/10.1097/00005110-200104000-00010

[14] McNeese-Smith, D. A content analysis of staff nurse descriptions of job satisfaction and dissatisfaction. Journal of Advanced Nursing. 1998; 29(6): 1332-1341. PMid:10354227 http://dx.doi.org/10.1046/j.1365-2648.1999.01018.x

[15] Hall, L. M., Doran, D. Nurses’ perceptions of hospital work environment. Journal of Nursing Management. 2007; 15: $264-273$. PMid:17359426 http://dx.doi.org/10.1111/j.1365-2834.2007.00676.x

[16] Garrett, D. K., \& McDaniel, A. M. A New Look at Nurse Burnout: The Effects of Environmental Uncertainty and Social Climate. The Journal of Nursing Administration. 2001; 31(2): 91-96. http://dx.doi.org/10.1097/00005110-200102000-00009

[17] Topf, M. Hospital noise pollution: an environmental stress model to guide research and clinical interventions. Journal of Advanced Nursing. 2000; 31(3): 520-528. PMid:10718870 http://dx.doi.org/10.1046/j.1365-2648.2000.01307.x

[18] Zimring, C. Stress and the designed environment. Journal of Social Issues. 1998; 37(1): 145-168. http://dx.doi.org/10.1111/j.1540-4560.1981.tb01061.x

[19] Bass, B. M. Bass and Stogdill's Handbook of Leadership: Theory, Research and Managerial Applications. Free Press: New York. 2008; 634-657.

[20] Cunningham, W. J. Teacher burnout - solutions for the 1980s: A review of the literature. The Urban Review. 1983; 15: 37-49. http://dx.doi.org/10.1007/BF01112341

[21] Vinge, H.F. Job engagement's paradoxical role in nurse burnout. Nursing and Health Sciences. 2007; 9(2): 107-111. http://dx.doi.org/10.1111/j.1442-2018.2007.00310.x

[22] Morelli, A. Implications of nursing station design on nurses' psychosocial health and work behavior. Undergraduate thesis, University of Gävle, Sweden. 2008.

[23] Verderber, S, Fine, D. Healthcare Architecture in an era of radical transformation. New Haven, CT, Yale University Press. 2000.

[24] McCullough, C. (Ed.). Evidence-Based Design for Healthcare Facilities. Rene Wilmeth, Pub. Sigma theta Tau International, Indianapolis IN. 2000.

[25] Becker, F. Nursing unit design and communication patterns: What is "real” work? Health Environments Research \& Design Journal. 2007; 1(1): 58-62.

[26] Garrett, D., K., McDaniel, A. M. A new look at nurse burnout: The effects of environmental uncertainty and social climate. Journal of Nursing Administration. 2001; 31(2): 91-96. http://dx.doi.org/10.1097/00005110-200102000-00009

[27] Zborowsky, T. \& Bunker-Hellmich, L. The impact of place on people and process: The integration of research on the built environment in the planning and design of critical care areas. Critical Care Nursing Quarterly. 2011; 34(4): $268-281$. PMid:21921712

[28] Erzberger, C., Prein, G. Triangulation: Validity and empirically-based hypothesis construction. Quality \& Quantity. 1997; 31: 141-142. http://dx.doi.org/10.1023/A:1004249313062

[29] Fitzpatrick, R., Boulton, M. Qualitative methods for assessing health care. Quality in Health Care. 1994; 3: 107-113. http://dx.doi.org/10.1136/qshc.3.2.107

[30] Zeisel, J. Inquiry by Design: Tools for Environment-Behavior Research. Monterey, CA: Brooks Cole Publishing Company. 1981.

[31] Fledge, H., Rose, M., Arck, P., Walter, O., Kocalevent, R., Weber, et al. The Perceived Stress Questionnaire (PSQ) reconsidered: Validation and reference values from different clinical and healthy adult samples. Psychosomatic Medicine. 2005; 67: 78-88. PMid:15673628 http://dx.doi.org/10.1097/01.psy.0000151491.80178.78

[32] Karasek, R. A., Theorell, T. Healthy work: Stress, productivity, and the reconstruction of working life. New York: Basic Books. 1990.

[33] Spence-Laschinger, H., Finegan, J., Shaimian, J. Promoting nurses'health: Effect of empowerment on job strain and work satisfaction, Nursing Economics. 2001; 19(2): 42-53.

[34] Doncevic, S., Romelsjo, A., Theorell, T. Comparison of stress, job satisfaction, perception of control, and health among district nurses in Stockholm and prewar Zagreb. Scandinavian Journal of Social Medicine. 1998; 26(2): 106-114. PMid:9658509 
[35] Morgan, D., Semchuk, K., Stewart, N., D’Arcy, C. Job strain among staff of rural nursing homes: A comparison of nurses, aides, and activity workers. Journal of Nursing Administration. 2002; 32(3): 152-161. http://dx.doi.org/10.1097/00005110-200203000-00008

[36] Brancoto, V. Enhancing psychological empowerment for nurses. Pennsylvania Nurse. 2003; 58(4): 10.4.

[37] Cunningham, W. J. Teacher burnout - solutions for the 1980s: A review of the literature. The Urban Review. 1983 ; $15: 37-49$. http://dx.doi.org/10.1007/BF01112341

[38] Parkes, K. Occupational stress among student nurses: A natural experiment. Journal of Applied Psychology. $1982 ; 6$ : 784-796. PMid:7153195 http://dx.doi.org/10.1037/0021-9010.67.6.784 